3.20 per cent.; tannin, 6.66 per cent.; extract, 34.40 per cent. ; moisture, 7.09 per cent.; mineral matter, 5.50 per cent. Although the flavour of the infusion yielded by coffee-tea compares unfavourably with both that of coffee and of tea, yet in view of the restorative and refreshing properties which it must possess on account of the excellent proportion of theine it contains it might be advantageously used by many individuals, and especially by those who are not able to tolerate coffee or tea.

NEW GRANULAR EFFERVESCENT PREPARATIONS.

(Allen and Hanburys, Plough-Court, lombard-Street, E.C.)

Messrs. Allen and Hanburys have effected an improvement in the manufacture of effervescent preparations which on reflection is more important than at first sight appears. It consists in the production of fineness and uniformity of the grain, by which not only are greater ease and accuracy of measurement secured, but also a readier solubility of the ingredients in water and a more equal distribution of the gas resulting on their admixture in solution are obtained. In addition, the bottles are conveniently provided with a measure stopper, which is made to hold one-sixth of an ounce-a minimum dose in each case of the active ingredient. With the view of putting these claims to the test we measured by means of the cup provided on the stopper two separate quantities of the drug, one from the upper and the other from the lower portion of the bottle. The preparation selected for this purpose was the ammonio-citrate of iron. In the one case 5.9 grains of ammonio-citrate of iron were found, calculated on the oxide obtained on igriting the sulphide produced with ammonia sulphide, and in the other $5 \cdot 7$ grains. Thus the results agreed to a fifth of a grain and the preparation was therefore found to present the advantages claimed. The specimens submitted to us included the following : phosphate of iron, 5 grains; citrate of magnesia; citrate of potash, 8 grains; ammonio-citrate of iron, 5 grains ; antipyrin, 5 grains; and sulphate of soda. These being submitted to tests gave satisfactory results. The degree of cold produced when the above preparations were dissolved in water was very perceptible, an observation which contributes testimony to the rapidity with which the ingredients dissolve.

\section{EUCALYPTUS OIL}

(Woods and Co., 18, Cowra-Chambers, GRenfeld-STREeT, ADELAIDE.)

The manufacturers of this oil state that it is distilled from the young leaves of the Eucalyptus cneorifolia-the "narrow-leaved" eucalyptus, a species grown on and peculiar to Kangaroo Island - at a lower temperature than is generally adopted. This statement is confirmed by our own observations in regard to its boiling point. Thus practically the whole of the oil distilled under $177^{\circ} \mathrm{C}$., the bulk of it distilling at from $172^{\circ}$ to $175^{\circ} \mathrm{C}$. The specific gravity of the oil proved to be 0.9111 . Submitted to further tests the oil gave equally satisfactory results. Bromide vapour gave an abundant yield of crystalline di-bromide $\left(\mathrm{C}_{10} \mathrm{H}_{18} \mathrm{OBr}_{2}\right)$-a reaction which is regarded as very characteristic of eucalyptol. The oil is free from irritating constituents and singularly purequalities which render it well adapted for inhalation and other medicinal purposes.

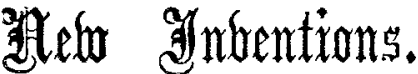

\section{AN IMPROVED MOUTH PROP OR GAG.}

SINCE the introduction of this mouth prop, two years zago, Messrs. Mayer and Meltzer, at my suggestion, have made several alterations in the original design which have materially added to its usefulness. Br curving the horizontal limbs the tooth mounts are more closely approximated, thereby facilitating the adjustment. A modification in the shape of the tooth mount adapting it to the requirements of edentulous cases has proved so convenient for all variations in dentition that it has been selected as the standard pattern. The smaller design is still supplied if desired. By freely lubricating the pivots and by separating the horizontal bars to the

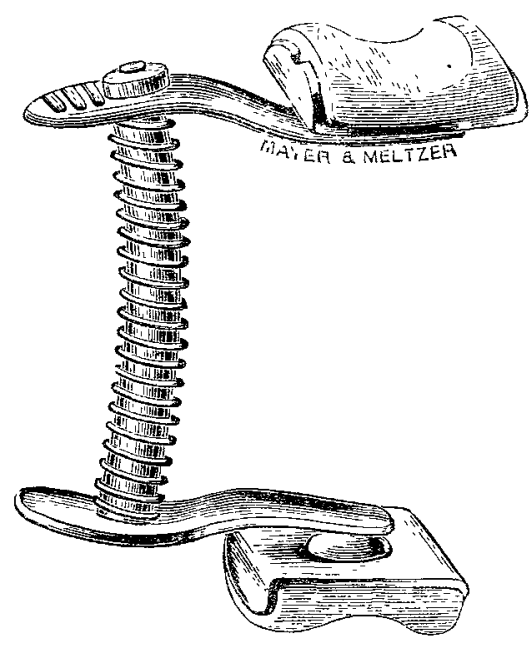

widest limits of the jaws during adjustment its security and action are fully assured, whilst very slight pressure with thumb and finger on the roughened projections will dis. engage it at once.

WYATT WTNGRAVE Assistant Surgeon, Central London Throat and Assistant Surgeon, Central Londonton.st., Gordon-sq., W.C.
Tar Hospital.

\section{MEDICO - PSYCEHOLOGICAL ASSOCIATION OF GREAT BRITAIN AND IRELAND.}

THE fifty-second annual meeting of this association was held at the Palace Hotel, Buxton, on Friday, July 28th, under the presidency of Dr. Murray Lindsay. At the business meeting in the morning many important subjects were discussed and a new edition of the Handbook for Nurses and Attendants on the Insane, prepared by a committee of the association, was announced. An important report was issued by the Educational Committee, which stated that several universities and licensing bodies now make an examination in mental diseases a compulsory subject for their degrees and diplomas. The Dietary Committee presented their report, but the discussion on the new rules was postponed until the November meeting. In the afternoon the president delivered the annual address, in which he dealt with the admission of female members to the association, the question of superannuation, the work of county councils, and the long hours of duty in asylums. He advocated the better equipment of county asylums by providing pathologists and rooms for research, and an increase in the staff of medical officers. He also dealt with the lunacy laws and the strengthening of the Lunacy Commission by an increase in the number of commissioners and the substitution of medical for legal commissioners. The address included remarks on the administration of asylums by county councils, showing that they are realising their new duties and progressing on the lines of advance, the London County Council being specially referred to as being in the front rank as regarded asylum management. The business being over, Dr. Robertson conducted a party of members over the baths, which, together with the Pavilion gardens and the Union and Golf Clubs, were thrown open to members during their stay in Buxton. In the evening the annual dinner was held, members of the county council and the Derby County Asylum committee and many local medical men being present as guests. On Saturday an excursion to Chatsworth, Haddon Hall and Blakewell Church brought to a close a most successful meeting. 